2014

\title{
IONIC LIQUID EXTRACTION UNVEILS PREVIOUSLY OCCLUDED HUMICBOUND IRON IN PEAT POREWATER
}

Timothy J. Veverica

Michigan Technological University

Follow this and additional works at: https://digitalcommons.mtu.edu/etds

Part of the Analytical Chemistry Commons, Biogeochemistry Commons, and the Ecology and Evolutionary Biology Commons

Copyright 2014 Timothy J. Veverica

\section{Recommended Citation}

Veverica, Timothy J., "IONIC LIQUID EXTRACTION UNVEILS PREVIOUSLY OCCLUDED HUMICBOUND IRON IN PEAT POREWATER", Master's Thesis, Michigan Technological University, 2014.

https://doi.org/10.37099/mtu.dc.etds/872

Follow this and additional works at: https://digitalcommons.mtu.edu/etds

Part of the Analytical Chemistry Commons, Biogeochemistry Commons, and the Ecology and Evolutionary Biology Commons 
IONIC LIQUID EXTRACTION UNVEILS PREVIOUSLY OCCLUDED HUMICBOUND IRON IN PEAT POREWATER

\title{
By
}

Timothy J. Veverica

\begin{abstract}
A THESIS
Submitted in partial fulfillment of the requirements for the degree of

MASTER OF SCIENCE

In Applied Ecology
\end{abstract}

MICHIGAN TECHNOLOGICAL UNIVERSITY

2014

(C) 2014 Timothy J. Veverica 

This thesis has been approved in partial fulfillment of the requirements for the Degree of MASTER OF SCIENCE in Applied Ecology.

School of Forest Resources and Environmental Science

\author{
Thesis Co-Advisor: $\quad$ Dr. Evan S. Kane \\ Thesis Co-Advisor: $\quad$ Dr. Amy M. Marcarelli
}

Committee Member: $\quad$ Dr. Sarah A. Green

School Dean: Dr. Terry L. Sharik 



\section{Table of Contents}

Preface

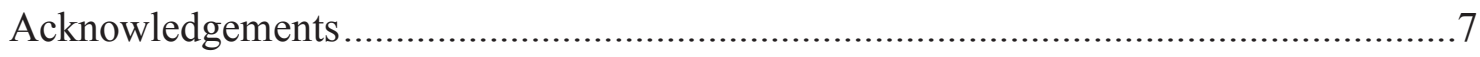

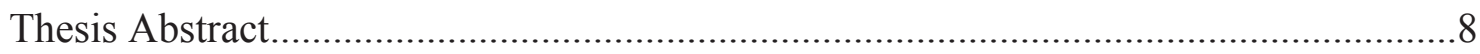

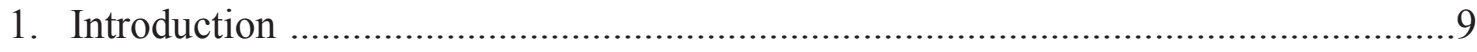

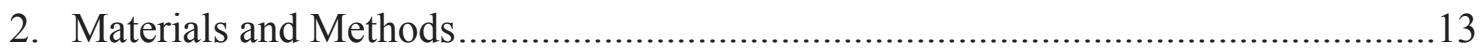

2.1. Study Sites and Sampling Protocols …………...........................................13

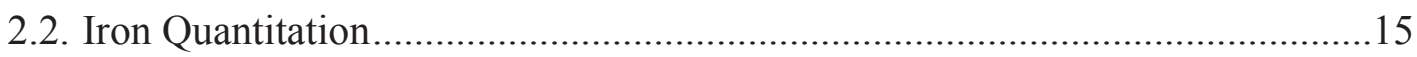

2.2.1 Quality Contol .........................................................................15

2.2.2 Ionic Liquid Extraction..................................................................... 15

2.2.3 o-phenanthroline ...........................................................................17

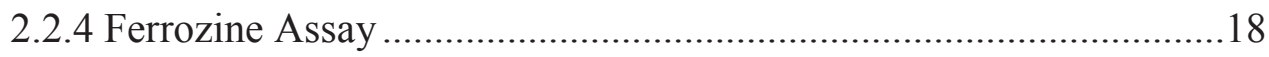

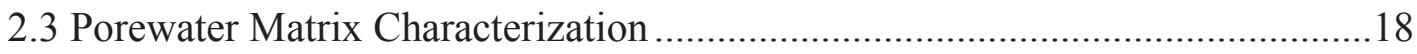

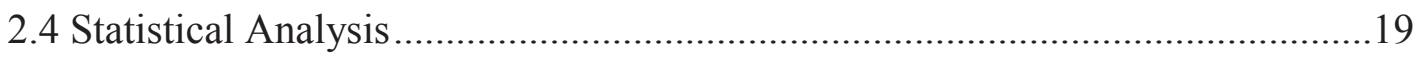

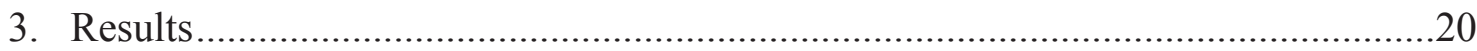

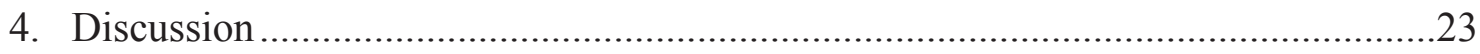

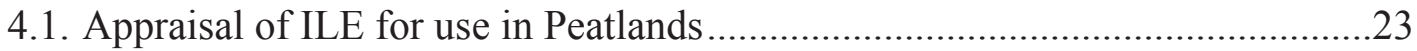

4.2. DOM Interference on Spectrophotometric Methods-Advantages of ILE.......24

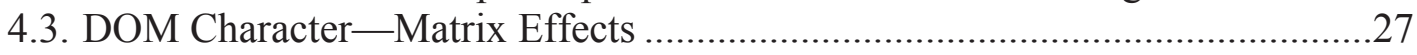

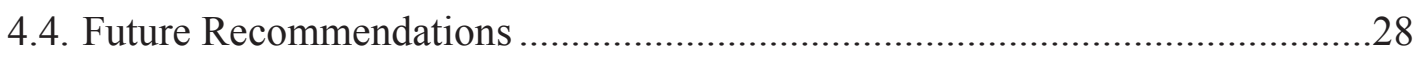

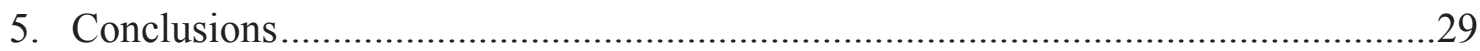

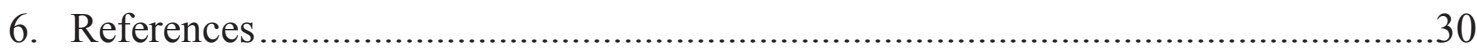

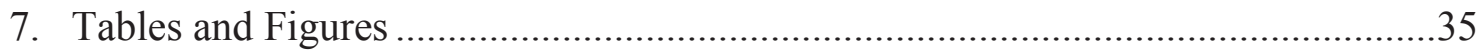

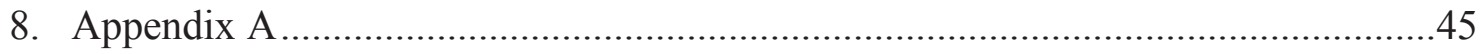

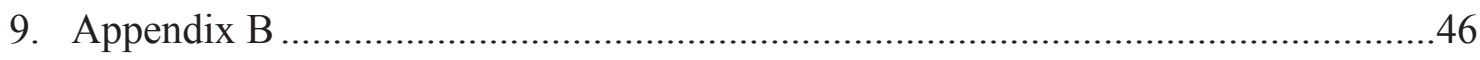




\section{Preface}

This Thesis is submitted in partial fulfillment of the degree of Master of Science in Applied Ecology at Michigan Technological University. The research described herein was conducted under the supervision of Dr. Evan Kane through the School of Forest Resources and Environmental Science and the USDA Forest Service Northern Research Station with additional supervision and assistance from Dr. Amy Marcarelli (Michigan Technological University School of Biological Sciences) and Dr. Sarah Green (Michigan Technological University Department of Chemistry). This is original work written by the lead author and is in preparation for submission for publication. The experimental procedures described herein were performed by the lead author with assistance from Dr. Kane; data analysis was performed by the lead author, Dr. Kane, and Dr. Amy Marcarelli. Dr. Sarah Green assisted with the design and optimization of the extraction scheme and provided great insight into the kinetics of the reactions described herein. Drs. Kane, Marcarelli, and Green provided substantial editorial comments which have helped shape this document. 


\section{Acknowledgments}

I owe a great debt of gratitude to my wife, Heather, who has been an endless source of encouragement and support throughout this work, and to my parents who set me on this path long ago. I am also grateful for the enthusiasm, encouragement, and thoughtful insight from my committee - this thesis, and the forthcoming article have benefitted endlessly from your input and your patient advice. I received invaluable advice in multivariate statistics from Rasmus Bro, Rose Cory, and the team at Eigenvector Research. I thank Brian Fisk, Eryn Grupido, Sam Mosier, Kayla Griffith, and Karl Meingast for help in the lab. I would also like to thank Lynette Potvin and Erik Lilleskov for coordinating help when it was most needed and for providing a safe, organized lab space to work in. This research was supported by the Ecosystem Science Center at Michigan Tech and by the National Science Foundation. 


\begin{abstract}
$^{1}$
Extracellular iron reduction has been suggested as a candidate metabolic pathway that may explain a large proportion of carbon respiration in temperate peatlands. However, the $o$-phenanthroline colorimetric method commonly employed to quantitate iron and partition between redox species is known to be unreliable in the presence of humic and fulvic acids, both of which represent a considerable proportion of peatland dissolved organic matter. We propose ionic liquid extraction as a more accurate iron quantitation and redox speciation method in humic-rich peat porewater. We evaluated both $o$-phenanthroline and ionic liquid extraction in four distinct peatland systems spanning a gradient of physico-chemical conditions to compare total iron recovery and $\mathrm{Fe}^{2+}: \mathrm{Fe}^{3+}$ ratios determined by each method. Ionic liquid extraction was found to provide more accurate iron quantitation and speciation in the presence of dissolved organic matter. A multivariate approach utilizing fluorescence- and UV-Vis spectroscopy was used to identify dissolved organic matter characteristics in peat porewater that lead to poor performance of the $o$-phenanthroline method. Where these interferences are present, we offer an empirical correction factor for total iron quantitation by $o$-phenanthroline, as verified by ionic liquid extraction.
\end{abstract}

${ }^{1}$ The written work presented in this thesis is in preparation for submission to Soil Biology and Biochemisrty by T.J. Veverica, E.S. Kane, A.M. Marcarelli, and S.A. Green. 


\section{Introduction}

Peatlands represent critical terrestrial carbon stores that are protected by a combination of hypoxic and anoxic soil environments. These chemical conditions present an energetic challenge for microbial consortia in anaerobic environments which utilize alternative (to oxygen) terminal electron acceptors (TEAs) during heterotrophic metabolism. In anaerobic conditions, microbes preferentially reduce several alternative TEAs for respiration, with thermodynamic yield declining in the order: nitrate $\left(\mathrm{NO}_{3}{ }^{-}\right)$, manganese $\left(\mathrm{Mn}^{4+}\right)$, ferric iron $\left(\mathrm{Fe}^{3+}\right)$, sulfate $\left(\mathrm{SO}_{4}{ }^{2-}\right)$, and ultimately $\mathrm{CO}_{2}$. Although there is wide agreement that alternative TEA reduction is important for anaerobic decomposition, wide variation in the magnitudes of anaerobic $\mathrm{CO}_{2}$ production across studies suggests that there is high variability in facultative and obligate anaerobic processes that occur below the water table (Morris et al., 2011), particularly in the expected sequential reduction of TEAs (Vile et al., 2003; Dettling et al., 2006; Keller \& Bridgham, 2007; Knorr \& Blodau, 2009; Deppe et al., 2010; Kane et al., 2013). A growing body of literature implicates a missing pool of electron acceptors responsible for relatively high carbon mineralization rates in saturated peatland soils (Keller and Bridgham, 2007; Blodau et al., 2007; Gupta et al., 2013). For example, Estop-Aragones et al. (2012) found that only ca. 55\% of dissolved inorganic C production could be explained despite monitoring a suite of organic and inorganic dissolved TEAs. Because of this inability to account for all TEAs, comprehensive energy budgets for peatlands have remained elusive. 
Due to the chemical characteristics of peat porewater and methodological limitations, it is possible that underestimation of $\mathrm{Fe}^{3+}$ could account for the "missing" TEAs in peatlands. Peat porewater is rich in dissolved organic matter (DOM) consisting largely of an array of humified products of plant decomposition and microbial activity (Thurman, 1985; D'Andrilli et al., 2010; Tfaily et al., 2013). Humic and fulvic acids form stable coordination complexes with ferric iron (Antunes et al., 2007; Fuji et al., 2014). These complexes are effective extracellular electron acceptors in anaerobic environments, including peat (Benz et al., 1998; Dodla et al., 2009; Bauer et al., 2007; Lipson et al., 2010; Keller and Takagi, 2013). Therefore, it is likely that complexed iron and humic substances are important electron acceptors in peatlands, but unfortunately common methods for estimating ferric iron (cf. EPA method 8008) are known to be unreliable in the presence of humic and fulvic acids. For example, Skogerboe and Wilson (1981) drew attention to uncertainty surrounding complete development time of the spectrophotometric $o$-phenanthroline- $\mathrm{Fe}^{2+}$ complex when fulvic acids were present. More recently, Fujisawa et al. (2011) demonstrated that humic acids prevent development of the colored $o$-phenanthroline complex because complexation between iron and humic acids is more kinetically favorable than formation of the $\mathrm{Fe}^{2+}$-phenanthroline complex and thus precludes color formation. Incomplete reaction with $o$-phenanthroline may lead to skewed estimates of iron reduction in these systems and could explain why quantification of the sequential chain of observed electron acceptors in peatlands often does not explain much variability in anaerobic metabolism. This is an important consideration because a large body of wetland research has depended on 
spectrophotometric assays to quantitate total and ferrous iron, and ferric iron by mass balance (cf. Delaune et al., 2014).

General caveats pertaining to matrix interferences in spectrophotometric determination of total and ferrous iron have been explored in the past (Skogerboe and Wilson, 1981; Anastacio et al., 2008), but environmental samples can vary widely in their composition (e.g, Tfaily et al. 2013) and there is no consensus as to which methods are most appropriate for samples containing highly humified, complex DOM. For example, DeLaune et al. (2014) recommend that $o$-phenanthroline is applicable for Fe quantitation in wetland sediments and soil porewater, based on the perceived quantitative recoveries of iron. Anástacio et al. (2008) compared the performance of $o$-phenanthroline with that of another popular reagent for iron, ferrozine, and also recommended $o$-phenanthroline across a wide range of ecosystems, including those with clay-sorbed amorphous iron oxides. Lipson et al. (2010) reported total Fe recoveries in Arctic peat soil using $o$ phenanthroline that were not significantly different from direct quantitation using inductively-coupled plasma methods. Other work has used the ferrozine assay to estimate iron redox in natural systems (Lovely and Philips, 1986; Pepper et al., 2010; Keller and Takagi, 2013). Despite reports of reliable results, both assays have been shown to experience interference in the presence of both model compounds and environmental DOM, including humic acids (Guo et al., 2008; Yamamoto et al., 2010; Fujisawa et al., 2011). Because iron reduction is energetically sufficient to completely oxidize organic matter under anoxic and hypoxic conditions (Lovely and Phillips, 1986; 
Lipson et al., 2010), incomplete iron quantitation could potentially explain a large proportion of peatland anaerobic metabolism, especially if DOM-Fe ${ }^{3+}$ complexes are utilized as TEAs, as Estop-Aragones et al. (2012) suggest (see also Lipson et al., 2010; Keller and Takagi, 2013). Therefore, to accurately appreciate the role iron plays in anaerobic metabolism in bogs and fens it is important to critically evaluate spectrophotometric determination of iron in the challenging matrix of peat porewater and to identify conditions where spectrophotometric approaches are not suitable.

To offer an alternative means of iron extraction and subsequent direct quantitation in humic-rich matrices, we adapted an ionic liquid extraction (ILE) method that utilizes an acid organophosphorous compound, following methods described by Pepper et al. (2010). This method has long been used in industrial effluent cleanup and metal reclamation (e.g., Belkouche and Didi, 2005; Guezzen and Didi, 2012; and references therein), and provides quantitative extraction of ferric iron independent of DOC concentration (Pepper et al. 2010). The extraction portion of the ILE method proceeds via three-step mechanism. At low $\mathrm{pH}, \mathrm{H}^{+}$ions donated to humic-Fe complexes cause the release both $\mathrm{Fe}^{2+}$ and $\mathrm{Fe}^{3+}$ ions. Ferric iron is then chelated by three bis-2-ethylhexyl phosphoric acid molecules. Formation of the $\mathrm{Fe}^{3+}$-tris(bis-2-ethylhexyl phosphate) complex is kinetically preferable to reformation of organo-ferrate complexes by a wide range of model organic matrices (Pepper et al., 2010), and the affinity of bis-2-ethylhexyl phosphate for $\mathrm{Fe}^{3+}$ is strongly favored over complexation with $\mathrm{Fe}^{2+}$. Phase separation using $n$-heptane ensures optimal partitioning of the $\mathrm{Fe}^{3+}$-tris(bis-2-ethylhexyl phosphate) 
complex into the organic phase, leaving $\mathrm{Fe}^{2+}$ behind in the aqueous phase. The extracted ferric iron is back-extracted into aqueous media with strong acid for analysis and both aqueous ferric and ferrous iron are directly quantitated using inductively-coupled plasma optical emission spectrometry (ICP-OES). Given the evidence for reliable quantitative performance in highly chelating matrices, ILE may present a novel way of tracking iron redox in the challenging peat porewater matrix. Here, we evaluated interference effects on the quantitation of ferrous and total iron in peat porewater from a variety of peatland environments, from rich fen to bog. Performance of the $o$-phenanthroline method was compared to the ionic liquid extraction method in complex environmental matrices and in deionized water. In this study, we address three questions.

1. Is the $o$-phenanthroline method suitable for iron quantitation and oxidation state speciation in northern peatlands?

2. Can a novel ionic liquid extraction method provide improved quantitation and iron speciation in these systems?

3. Can UV-Vis and fluorescence spectroscopy be used to identify DOM character corresponding to reduced $o$-phenanthroline method performance in peat porewater?

\section{Materials and Methods}

\subsection{Study Sites and Sampling Protocol}

Study sites consisted of four locations encompassing a wide gradient of porewater chemistry and dissolved organic matter content and character (Table 1), including a rich 
fen from interior Alaska, USA (see Kane et al., 2010), a rich cedar fen peatland, and a water table manipulation in a bog in northern Michigan, USA (see Potvin et al. 2014). Sampling at the bog site was divided equally into plots with unaltered and lowered water table positions.

We collected porewater samples from a depth of $20 \mathrm{~cm}$ below the peat surface through established piezometers into airtight, headspace-free containers. All piezometers were purged prior to collection, and were outfitted with $120 \mu \mathrm{m}$ Nitex mesh to avoid sampling coarse particulate matter. In the rich fen peatland, porewater samples were harvested with a syringe, injected into pre-evacuated vials, and shipped overnight on ice to the USDA Forest Service Northern Research Station in Houghton, MI for analysis. Samples from all other sites were harvested in the same manner, but were analyzed within 2 hours of collection.

To evaluate discrete interference effects of increased humification and reduction of DOM over time, porewater samples from the bog site (two from the high water table treatments, two from the low) were harvested as above and transferred under $\mathrm{N}_{2}$ into serum vials, which were sealed and incubated in the dark at ambient temperature (total number $=16$ bottles for high and low water table treatments). Destructive harvests $(n=4)$ from these samples occurred at $0,7,21$, and $48 \mathrm{~d}$ for iron quantitation and organic matter characterization following the same methods as described for field samples

In the lab, sealed samples were placed in a positive-pressure glovebox (TDI International model 60245DG, Tucson AZ, USA), and the atmosphere was exchanged five times or more with zero-grade $\mathrm{N}_{2}$. As the samples equilibrated to laboratory 
temperature, extraction reagents were degassed and prepared under $\mathrm{N}_{2}$ to avoid the introduction of extraneous dissolved oxygen during the extraction process. After reaching ambient temperature, all samples were uncapped and filtered through $0.45 \mu \mathrm{m}$ sterile nylon membrane filters (AQ Brand Microsolv) and divided into two aliquots each, which were transferred to glass vials fitted with Teflon-faced septa and analyzed using the two different iron quantitation methods

\subsection{Iron quantitation}

\subsubsection{Quality Control}

To compare the performances of $o$-phenanthroline and ILE in the absence of DOM and to capture any inadvertent oxidation during sample handling, duplicate quality

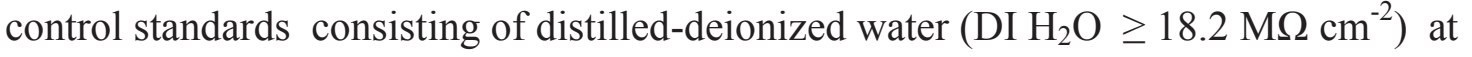

either $50: 50,80: 20,85: 15$, or $90: 10 \mathrm{Fe}[\mathrm{II}]: \mathrm{Fe}[\mathrm{III}]$ at $1,1.5,2$, and $3 \mathrm{mg} \mathrm{L}^{-1}$ total Fe were prepared. Duplicate $5 \mathrm{~mL}$ aliquots of each quality control standard were transferred to glass vials fitted with Teflon-faced septa for extraction, and identical aliquots were analyzed simultaneously by $o$-phenanthroline.

\subsubsection{Ionic Liquid Extraction}

The ILE procedure was identical to that described by Pepper et al. (2010), except that the volumes of sample and reagents were increased to accommodate our instrument requirements and the time allotted for forward extraction was extended to $2 \mathrm{~h}$ to ensure maximal mixing of this larger volume. Thus, $5 \mathrm{~mL}$ of sample was transferred to an extraction vial, to which $15 \mathrm{~mL}$ of $0.67 \mathrm{~N} \mathrm{HCl}$ (ACS grade; Fisher Scientific) was added, 
followed by the addition of $20 \mathrm{~mL} 0.1 \mathrm{M}$ bis-2-(ethylhexyl) phosphoric acid (hereafter HDEHP; 97\% Sigma Aldrich) in $n$-heptane (HPLC grade, Acros Organics). A reagent blank consisting of only DI water was also included to correct for trace iron found in $\mathrm{HCl}$. Laboratory trials in $\mathrm{DI} \mathrm{H}_{2} \mathrm{O}$ and environmental matrices alike confirmed that extraction vessel geometry and resulting liquid turbulence greatly influenced the rate at which a mass transfer-limited extraction such as this proceeds, and that mixing is essential for results to be reliable. In our case, optimal mixing was accomplished by laying the vials on their side during shaking. The forward extraction of $\mathrm{Fe}^{3+}$ into the organic phase was accomplished by laying extraction vials on their sides to maximize the organic-aqueous interface, and shaking at $500 \mathrm{rpm}$ on a shaker table for two hours. Following forward extraction of $\mathrm{Fe}^{3+}$, resulting emulsions were allowed to clear, and a 10 $\mathrm{mL}$ aliquot of the aqueous phase containing the $\mathrm{Fe}^{2+}$ fraction was then transferred into a high-density polyethylene centrifuge tube (BD Falcon) for storage and analysis. A 10 $\mathrm{mL}$ aliquot of the organic phase was transferred to a vial containing $10 \mathrm{~mL}$ of $4.0 \mathrm{~N} \mathrm{HCl}$, and was shaken for 20 minutes at $500 \mathrm{rpm}$ to back-extract $\mathrm{Fe}^{3+}$ into the aqueous phase. The resulting aqueous phase in the back-extraction tube was similarly transferred to a high-density polyethylene centrifuge tube for storage and analysis. Quantitation of extracted $\mathrm{Fe}^{2+}$ and $\mathrm{Fe}^{3+}$ and un-extracted total iron were carried out on a Perkin-Elmer Optima 7000DV ICP-OES in the Michigan Technological University Stable Isotope Laboratory. The values reported are the average of five injections per sample, and instrument error was calculated to be $\pm 10 \%$ of the mean. 


\subsection{3 o-phenanthroline}

For comparison, total $\mathrm{Fe}$ and $\mathrm{Fe}^{2+}$ were also measured using the $o$-phenanthroline method (Hach Co., Loveland CO, USA; Methods 8146 and 8008, respectively) under ambient atmosphere at laboratory temperature. Spectrophotometric methods were scaled for use with a 96-well plate reader (see, for example, Sinsabaugh et al., 2000). Samples and corresponding matrix spikes were diluted 1:10 with DI $\mathrm{H}_{2} \mathrm{O}$ and were reacted with $0.16 \% o$-phenanthroline (for ferrous iron, Hach Method 8008), and $0.16 \% o$ phenanthroline $p$-toluenesulfonic acid salt supported by a reducing agent consisting of sodium thiosulfate, sodium hydrosulfate, sodium citrate, and sodium metabisulfite (total iron, Hach method 8146), corresponding with the beginning of ionic liquid extraction. The method detection limits of these colorimetric assays were $0.01 \mathrm{mg} \mathrm{L}^{-1}$ in the 1:10diluted samples. Reaction progress was monitored by reading the absorbance $(510 \mathrm{~nm})$ of standards and samples at $15 \mathrm{~min}, 45 \mathrm{~min}, 60 \mathrm{~min}, 3 \mathrm{hrs}$, and $24 \mathrm{hrs}$. Laboratory trials indicated that the 3 minute reaction time recommended by the manufacturer was insufficient for environmental samples from peatland matrices to reach completion in either colometric assay, though 15 minutes was sufficient to allow absorbances of matrixfree standards to stabilize. DOM-rich samples required $3 \mathrm{hrs}$ for stable color formation, and all results from $o$-phenanthroline methods reported in this study are from the $3 \mathrm{hr}$ measurement. During the time between readings, plates were kept wrapped in foil to prevent photochemical reactions (DeLaune et al., 2013). We analyzed reagent-free samples simultaneously with reacted samples to correct for any background absorbance 
that would otherwise skew results. Standards used to build the calibration curves for the colorimetric methods were submitted to the Michigan Tech Stable Isotope Laboratory for concentration verification by ICP-OES, and the $o$-phenanthroline calibration curves were built from these actual concentrations.

\subsubsection{Ferrozine assay}

For further intercomparison, $\mathrm{Fe}^{2+}$ and total $\mathrm{Fe}$ quantitation were performed on a subset of bog samples $(n=4)$ following the methods outlined in Viollier et al (2000).

\subsection{Porewater Matrix Characterization}

All matrix characterizations occurred simultaneously with iron quantitation. Filtered aliquots of sample were analyzed for organic acid and anion content on a Dionex ICS 2000 ion chromatograph (Dionex Corporation, Bannockburn, IL, USA). Ultravioletvisible (UV-Vis) absorbance and fluorescence spectra (Excitation-Emission Matrices; EEMs) were both measured simultaneously with a Horiba-Jobin Yvon Aqualog C (Horiba Corporation, Edison, NJ, USA). Run parameters were Excitation: 240-600 nm by $3 \mathrm{~nm}$ increments; Emission: 212-608 $\mathrm{nm}$ by $3 \mathrm{~nm}$ bandpass; integration time $=0.25 \mathrm{~s}$. Samples with absorbance greater than 0.6 at $\lambda_{254}\left(\mathrm{~A}_{254}>0.6\right)$ were diluted with $\mathrm{DI} \mathrm{H}_{2} \mathrm{O}$, such that they were $0.20<\mathrm{A}_{254 \text { (sample) }}<0.6$ in order to satisfy the assumption of detector linearity required by modeling (Stedmon and Bro, 2008; Lawaetz and Stedmon, 2009). Absorbance, excitation and emission corrections were performed simultaneously with measurement against an integrated reference detector. Resulting UV-Vis data were later 
corrected with a scalar absorbance correction factor (the inverse of diluted concentration) for data analysis, as laboratory trials indicated that $\mathrm{A}_{254}$ and other indices of interest vary linearly in these sample matrices. Preliminary exploration found that the measured fluorescence intensities of DOM in these systems also vary linearly with dilution within this range, thus the same scalar correction factor was applied to EEMS fluorescence intensities. Further preprocessing steps following the scheme presented in Lawaetz and Stedmon (2009) and Singh et al. (2013) were employed. The resulting EEM fluorescence intensities were normalized to the integral of the water Raman peak (Ex 350/Em 371428) of the sample (akin to normalization to an internal standard). We normalized the resulting fluorescence intensities to an external, ultrapure Raman peak water standard (Starna Cells, Atascadero, CA, USA), integrated similarly to the sample Raman peak and collected daily. EEMs were then analyzed for fluorescence index (Johnson et al. 2011), an index of humification $\left(\mathrm{H}_{\mathrm{P}}\right.$; He et al. 2013) and for an index of DOM redox state derived from Miller et al. 2006 using the area in a $10 \mathrm{~nm}$ x $10 \mathrm{~nm}$ window under the component peak maxima (as a \% total EEM fluorescence).

\subsection{Statistical Analysis}

Linear regressions of ILE and $o$-phenanthroline total iron recovery versus total iron determined directly by ICP-OES were performed using SAS (SAS Institute Inc., Cary, NC, USA) to evaluate the performance of either method in both DI water $(n=5)$ and environmental matrices $(\mathrm{n}=20)$. All regression analyses were considered significant 
at $\alpha=0.05$, and t-tests were used to identify significant (at $\alpha=0.05$ ) departure from $\mathrm{y}=\mathrm{x}$ as an indicator of method efficacy.

Multivariate approaches were used to characterize variation in sample matrices. Parallel Factor Analysis (PARAFAC) was used to decompose 121 fluorescence EEMs from a variety of peatlands into discrete fluorescence components following the methods of Stedmon and Bro (2008) and Kothwala et al (2013). Principal Component Analysis (PCA) was used as a means of arranging sample chemical matrices for qualitative exploration (Kothawala et al., 2013; Bro and Smilde, 2014) incorporating variables from Table 1 and including \% total iron recovered by $o$-phenanthroline. Partial Least Squares analysis (PLS) was performed to identify correlative factors that best explain $o$ phenanthroline method performance using the same variables as for the PCA model, but constraining the y-block to be $\%$ total iron recovered by $o$-phenanthroline. Agglomerative Hierarchical Cluster Analysis (HCA) was performed on the PCA model to identify clusters of chemically similar samples using the K Nearest Neighbor approach.

PARAFAC, PCA, and PLS, and HCA were performed using PLS_Toolbox (Eigenvector Research, Inc., Wenatchee, WA) in Matlab (R2014a).

\section{Results}

The $o$-phenanthroline method routinely underquantified total iron in samples with DOM matrix (Fig 1; significantly different from ICP-OES; paired t-test $p<0.001$ ) but remained quantititative in DI water (data not shown — not significantly different from 
ICP-OES; paired t-test $\mathrm{p}=0.199$ ). ILE was not significantly different from ICP-OES in either DI water (paired t-test $\mathrm{p}=0.453$ ) or in environmental matrices (Fig 1; paired t-test $\mathrm{p}=0.21$ ). Because $o$-phenanthroline uses total iron to estimate $\mathrm{Fe}^{3+}$ by mass balance, this method estimated approximately $87 \%$ less $\mathrm{Fe}^{3+}$ than ILE (range $=53-100 \%$ less; Fig 2.), despite the tendency for $\mathrm{Fe}^{3+}$ to be slightly over-quantitated relative to $\mathrm{Fe}^{2+}$ in quality control standards (data not shown; average difference $=8.3 \%$, paired t-test $\mathrm{p}=0.05$ ). ILE did not show any inadvertent oxidation in the QC standards (average difference $=0.6 \%$, paired t-test $\mathrm{p}=0.50$ ), indicating that anaerobic conditions were persistent throughout each extraction. Ferrozine recovered $\sim 30 \%$ less total Fe than ILE (68.9-69.7\% recovery) and was in fact out-performed by $o$-phenanthroline in this regard (o-phenanthroline recovered $81.5-88.5 \%$ total $\mathrm{Fe}$ in the subset of samples).

Samples represented a range of DOC concentrations (32.6-172.3 $\left.\mathrm{mg} \mathrm{L}^{-1}\right)$ and $\mathrm{SUVA}_{254}\left(2.89-4.72 \mathrm{~L} \mathrm{mg}-\mathrm{C}^{-1} \mathrm{~cm}^{-1}\right)$. Concentrations of the organic acids formate, acetate, prorpionate and oxalate were below detection limits $\left(0.02 \mathrm{mg} \mathrm{L}^{-1}\right)$ : these data were thus not included in further analyses. A PARAFAC model described $>99 \%$ of fluorescence in all EEMs and was able to identify 6 component classes (Fig 3, Table 2). Careful examination of residual fluorescence in EEM landscapes did not reveal any other component classes.

Principal component analysis (Fig 4, Table 3.) found that samples sorted along a redox and carbon source gradient. Positive loadings along PC 1 corresponded to an increasing redox index (more reduced samples), and an increasing proportion of red- 
shifted fluorophores $(\% \mathrm{C} 2$ and $\% \mathrm{C} 3)$. Positive loadings along PC2 corresponded to variation in indices of humification (increasing $\mathrm{H}_{\mathrm{P}}$ and $\mathrm{E} 4$; decreasing FI) and differences in the DOC content in the samples. The time course of the incubation experiment sorts along PC1 indicating that DOM in the samples became both more reduced and humified throughout the course of the experiment.

A PLS model with the y-block loadings constrained to $o$-phenanthroline method performance (as \% total iron recovery vs ICP) was constructed. X-block loadings (sample chemical parameters from Table 1) with significant predictive power are projected further away from the origin, as opposed to orthogonal loadings which are nearest the origin (Fig. 5). The loadings which are located most opposite to the vector describing method performance and which project the furthest Euclidean distance from the origin (Table 4) comprise the most probable matrix interferences for the $o$-phenanthroline method in this dataset. These loadings were found to be $\mathrm{H}_{\mathrm{P}}, \% \mathrm{C} 3 \mathrm{RI}$, and $\% \mathrm{C} 2$ (Figure 5). A simple linear regression of $\mathrm{H}_{\mathrm{P}}$ versus $o$-phenanthroline (Fig. 6) confirms that this particular index of humification is predictive of $o$-phenanthroline performance. Regressions of total Fe recovery by $o$-phenanthroline against RI, $\% \mathrm{C} 2$, and $\% \mathrm{C} 3$ within the context of the full breadth of samples were not significant at $\alpha=0.05$ (RI: $p=0.4150 ; \% \mathrm{C} 2$ : $p=0.8575$; $\% \mathrm{C} 3: \mathrm{p}=0.937)$. Samples from the rich fen and cedar swamp were consistent outliers, with higher than predicted total Fe recovery by $o$-phenanthroline in spite of the presence of these interferences (though total Fe recovery was still not quantitative). The HCA output confirms that these samples share chemical similarity with each other, but do not 
share similarity with the bulk of the dataset (not shown). The relationship between $o$ phenanthroline performance and Hp was still significant with the rich fen and cedar swamp data excluded $\left(\mathrm{R}^{2}=0.301, \mathrm{~F}=6.88, \mathrm{p}=0.018\right)$.

\section{Discussion}

\subsection{Appraisal of ILE for Use in Peatlands}

ILE was found to be a more accurate method than $o$-phenanthroline for iron quantitation and speciation in peat porewater across a gradient of physico-chemical conditions. To our knowledge, this study is the first appraisal of this extraction scheme in peatlands. The greater accuracy provided by ILE may be useful in tracking iron biogeochemistry in these systems that has otherwise remained elusive. For example, ILE detected $\mathrm{Fe}^{3+}$ in all environmental samples assayed, and throughout the course of an incubation where $o$-phenanthroline indicated that all iron was $\mathrm{Fe}^{2+}$. Further studies using this method instead of $o$-phenanthroline may indicate the persistence of humic-bound $\mathrm{Fe}^{3+}$ as an energetic reservoir following, e.g., water table drawdown and subsequent rewetting (Estop-Aragones et al., 2013). Mechanistic insight into humic-iron redox interactions could perhaps also be gained through use of ILE rather than $o$-phenanthroline. Specifically, this approach could prove useful for close examination of the reaction scheme proposed by Page et al. (2012). 


\subsection{DOM Interference on Spectrophotometric Iron Methods-Advantages of ILE}

ILE appears to be an intrinsically better method for quantitation of iron in highly humified, DOM-rich sample matrices than spectrophotometric approaches for three reasons: lower reaction $\mathrm{pH}$, smaller chelating agent size, and a more sensitive detection method. The $o$-phenanthroline complexation reaction proceeds optimally at pH 3-5 (Komadel and Stucki, 1988; Amonette and Templeton, 1998) while the ferrozine assay, a similar spectrophotometric method that has been utilized for iron quantitation and redox partitioning in some peatland systems (Viollier et al., 2000; Keller and Takagi, 2013) occurs at $\mathrm{pH} \sim 9.5$. There is some debate as to the overall reliability of this method as well (e.g., Anástacio et al., 2008; Guo et al., 2008; Hu 2011; DeLaune et al., 2014). In our samples total Fe assayed by ferrozine was in fact out-performed by $o$-phenanthroline. The reason for reduced ferrozine performance in the presence of peat humic acids may be explained by the effect of reaction $\mathrm{pH}$ on humic/fulvic Fe binding, and thus the complexation equilibrium that ferrozine might reach with iron in the sample matrix. In model humic substances, higher $\mathrm{pH}(\mathrm{pH}>6)$ has been shown to lead to tighter binding in metal-humic complexes as the predominant binding sites shift away from carboxyl groups toward phenolics (Catrouillet et al., 2014). This shift in binding site species is accompanied by a reduction in the overall number of sites in humic acids (Fuji et al. 2014), likely corresponding to the relatively smaller number of suitable phenolic sites vs. carboxylic sites overall (Catrouillet et al., 2014, Fuji et al., 2014). Because the ferrozine assay is carried out at a reaction $\mathrm{pH}$ of 9.5 , the majority (ca. $60 \%$, 
Catrouillet et al., 2014) of dominant binding sites in the sample matrix will shift toward phenolic groups, while some previously-complexed iron will enter the solution where it is readily quantitated. A fraction of humic-complexed Fe will remain unquantifiable by ferrozine because it is either too tightly bound or else stearically inaccessible (Guo et al., 2007; Hu 2011). Complementary research within the bog system investigated in this study suggests that $\mathrm{H}_{\mathrm{P}}$ is strongly correlated with Folin-Coicetreau assayed phenolics $(\mathrm{r}=0.66 ; \mathrm{p}<0.001 ; \mathrm{n}=92)$, suggesting that further matrix exploration may be necessary. The $o$-phenanthroline assay is carried out at a more optimal $\mathrm{pH}$ to strip DOM-complexed Fe. Based on this information alone $o$-phenanthroline should experience greater total $\mathrm{Fe}$ recoveries than ferrozine but would theoretically still be less effective in this regard than ILE, which proceeds at $\mathrm{pH} \sim 1$.

Both $o$-phenanthroline and ferrozine depend on the ability of a colorimetric complex to form with Fe. This mechanism is limited in humic- and fulvic-rich systems wherein the predominant metal-DOM complexes are thought to exist as bidentate or tridentate conformations of large molecules with bulky functional groups that serve as binding sites (Catrouillet et al., 2014). These conformations exhibit considerable steric hindrance from the standpoint of either spectrophotometric assay, effectively limiting quantitation to free $\mathrm{Fe}$ (e.g., Fujisawa et al., 2011) and an unpredictable portion which is accessible to the chelating agent. bis-2-ethylhexyl phosphoric acid is an aliphatic 
molecule and so exhibits less steric hindrance, which likely further improves extraction efficiency.

Both $o$-phenanthroline and ferrozine rely upon spectrophotometric determination by chomophoric absorbance (Viollier et al., 2001; Delaune et al., 2013). Either of these methods could feasibly experience interference from inner filter effects in especially DOM-rich matrices (Kothwala et al., 2012), though DOM typically does not absorb strongly in either the $562 \mathrm{~nm}$ (ferronzine) or $510 \mathrm{~nm}$ (o-phenanthroline) regions, and a heuristic correction for these effects is achieved by simply subtracting the absorbance of reagent-free samples alongside samples undergoing iron quantitation. More important than the potential for slight inner filter effects is the fact that analytical equipment for these methods is inherently less sensitive than ICP-OES, and especially less sensitive than ICP-MS methods. Because ILE utilizes these quantitation techniques, it offers superior precision over spectrophotometric methods.

The unpredictable endpoint of the $o$-phenanthroline-Fe reaction in systems rich in humic acids (Skogerboe and Wilson, 1981; Fujisawa et al., 2011) and the apparent inability of ferrozine to compete with plant polyphenols at circumneutral pH (Guo et al., 2007) suggests that humic substances in DOM pose challenges for either optical method. ILE offers an alternative approach for exploring iron biogeochemistry for applications where quantitative iron recoveries are needed, in systems where highly-chelating matrices may pose analytical challenges for spectrophotometric methods. 


\subsection{DOM Character-Matrix Effects}

Multivariate modeling of matrix effects on $o$-phenanthroline in this work suggests that successful quantitation and redox speciation of iron in peatlands depends less on DOM concentration than it does on the character of DOM. Humic and fulvic substances have been shown to chelate $\mathrm{Fe}^{3+}$ using fluorescence spectroscopy quenching assays (Antunes et al. 2007), and peat-derived humics and fulvics are among the most tenacious humic substances in regard to iron binding (Fuji et al. 2014). It is not surprising, then, that humic and fulvic-like fluorophores present in our sample matrices $\left(\mathrm{H}_{\mathrm{P}}, \% \mathrm{C} 2\right.$ and $\% \mathrm{C} 3$ ) corresponded to reduced $o$-phenanthroline method performance. The $\mathrm{H}_{\mathrm{P}}$ index presented the loading with the largest Euclidean distance away from the origin, in the direction most antagonistic to $o$-phenanthroline performance within our dataset, suggesting that $\mathrm{H}_{\mathrm{P}}$ may be a good way to determine if $o$-phenanthroline is an appropriate method for iron quantitation. Our data suggest that in the absence of $\% \mathrm{C} 2$ and $\% \mathrm{C} 3$ interferences, it is entirely likely that results from $o$-phenanthroline are accurate, though these components combined comprised $22-63 \%$ of fluorescence described by PARAFAC in these samples, suggesting that they are perhaps ubiquitous in peat porewater.

UV-Vis indices like $\mathrm{SUVA}_{254}$ and E4 are frequently utilized to deduce DOM character, particularly aromaticity (Worrall et al., 2002; Weishaar et al., 2003). In our dataset, E4 was a better indicator of differences in DOM between samples than $\mathrm{SUVA}_{254}$ but neither provided predictive capability with regards to $o$-phenanthroline performance as strong as $\% \mathrm{C} 2, \% \mathrm{C} 3$ or $\mathrm{H}_{\mathrm{P}}$. In a study encompassing 15 standard humic- and fulvic 
acid mixtures, Fuji et al. (2014) reported that aromaticity was a strong predictive factor of iron binding capacity and coordination complex stability. We have found that a UV-Vis index of oxygen content (E4) is a stronger predictor of $o$-phenanthroline method performance than aromaticity (proxied by $\mathrm{SUVA}_{254}$ ), which agrees in principle with the concept that humic and fulvic carboxylic groups participate in Fe binding (Catrououillet et al., 2014). In order to fully understand DOM-Fe interactions in peat porewater, investigations coupling ILE and spectrophotometric iron assays to NMR and high-field mass spectrometry in addition to fluorescence and UV-Vis spectroscopy (Tfaily et al., 2013) could provide greater mechanistic insight into site-dependent matrix effects.

In our dataset, it appears that $o$-phenanthroline is not well-suited for use in peatlands due in part to the preponderance of highly humified DOM. In other systems possessing relatively less humified or more aliphatic DOM (see, e.g., Kothwala et al., 2013), this method may be appropriate for quantitative studies of iron biogeochemistry.

\section{4 Future recommendations}

Providing that the presence of the peat-derived matrix interferences we found in these samples can be confirmed, we propose a simple linear correction factor for the $o$ phenanthroline method:

$$
\text { (Eq. 1) } \quad y_{\text {corr }}=1.6( \pm 0.23) x+0.83( \pm 0.82)
$$

Where $y_{\text {corr }}$ is the corrected total iron in peatlands, when $o$-phenanthroline is used 
and $x$ is the total iron previously quantitated using $o$-phenanthroline. Standard error for regression terms are given in parentheses. $\mathrm{R}^{2}=0.72 ; \mathrm{F}=46.93 ; \mathrm{p}<0.001$.

Method selection is obviously not limited to concerns regarding quantitative yield, but also with regards to analytical time and cost. $o$-phenanthroline and other colorimetric methods are considerably higher throughput, more facile, and less costly by far than ILE which requires specialized equipment and generates considerable amounts of hazardous chemical waste. The optical methods we investigated may be suitable for detecting seasonal trends in iron in natural systems or treatment effects in experimental systems, but we caution against using the $o$-phenanthroline method in studies investigating pools of electron acceptors in anaerobic metabolism.

\section{Conclusions}

An underestimation of total iron using the $o$-phenathroline method in peat porewater matrices has the potential to lead to an underestimate $\mathrm{Fe}^{3+}$ by up to $100 \%$. Matrix interferences in these systems were found to be the result of peat-derived humic and fulvic acids. Use of an ionic liquid extraction method to quantitate iron and elucidate the redox fraction of the iron was shown to be reliable in spite of these potential interferences and is recommended in these systems. An empirical correction factor between ICP-OES total Fe and $o$-phenanthroline total Fe in this work may inform studies of heterotrophic metabolism in humic-rich environments like peat porewater. 


\section{References}

Amonette, J.E., Templeton, J.C. 1998. Improvements to the quantitative assay of nonrefracotry minerals for Fe(II) using 1,10-phenanthroline. Clays and Clay Minerology 46:51-52.

Anastácio, A.S., Harris, B., Yoo, J.I., Fabris, J.W. Stucki, J.W. 2008. Limitations of the ferrozine method for quantitative assay of mineral systems for ferrous and total iron. Geochimica et Cosmochimica Acta 72:5001-5008.

Antunes, M.C.G., Pereira, C.C.C., Esteves da Silva, J.C.G. 2007. MCR of the quenching of the EEM of fluorescence of dissolved organic matter by metal ions. Analyitica Chimica Acta 595:9-18.

Bauer, M., Heitmann, T., Macalady, D.L., Blodau, C. 2007. Electron transfer capacities and reaction kinetics of peat dissolved organic matter. Environmental Science and Technology 41:139-145.

Benz, M., Schink, B., Brune, A. 1998. Humic acid reduction by Propionibacterium freudenreichii. Applied and Environmental Microbiology. 64: 4507-4512.

Belkouche, N.E., Didi, M.A., Villemin, D. 2005. Seperation of nickel and copper by solvent extraction using di-2 ethylhexylphosphoric acid-based synergistic mixture. Solvent Extraction and Ion Exchange 23:677-693.

Catrouillet, C., Devranche, M., Dia, A., Boughnik-Le Coz, M. Marsac, R., Pourret, O., Gruau, G. 2014. Geochemical modelling of Fe(II) binding to humic and fulvic acids. Chemical Geology 372:109-118

Cory, R.M., and McKnight, D.M. 2005. Fluorescence spectroscopy reveals ubiquitous presence of oxidized and reduced quinones in dissolved organic matter. Environmental Science and Technology 39:8142-8149.

D’Andrilli, J., Chanton, J.P., Glaser, P.H., Cooper, W.T. 2010. Characterization of dissolved organic matter in northern peatland soil porewaters by ultra high resolution mass spectrometry. Organic Geochemistry 41:791-799.

DeLaune, R.D., Reddy, K.R., Richardson, C.J., Megonigal, J.P. 2013. Methods in Biogeochemistry of Wetlands. ISBN: 978-0-89118-960-2. 
Deppe M, McKnight DM, Blodau C. 2010. Effects of short-term drying and irrigation on electron flow in mesocosms of a northern bog and an alpine fen. Environmental Science and Technology 44: 80-86.

Dettling MD, Yavitt JB, Zinde SH. 2006. Control of organic carbon mineralization by alternative electron acceptors in four peatlands, central New York State, USA. Wetlands 26:917-927.

Dingman, S.L., Koutz, F.R., 1974. Relations among vegetation, permafrost, and potential insolation in central Alaska. Arctic, Antarctic and Alpine Research 6, 37-42.

Dodla, S.K., Wang, J.J., Delaune, R.D., Breitenbeck, G. 2009. Carbon gas production under different electron acceptors in a frewshwater marsh soil. Chemosphere 76:517-522.

Drake HL, Horn MA, Wüst PK. 2009. Intermediary ecosystem metabolism as a main driver of methanogenesis in acidic wetland soil. Environmental Microbiology Reports 1:307-318.Dunnivant et al 1992

Estop-Aragones, C., Knorr, K.H., Blodau, C. 2012. Belowground in situ redox dynamics and methanogenesis recovery in a degraded fen during dry-wet cycles and flooding. Biogeosciences Discussions 9:11655-11704.

Fuji, M., Imaoka, A., Yoshimura, C., Waite, T.D. Effects of molecular composition of natural organic matter on ferric iron complexation at circumneutral pH. Environmental Science and Technology 48:4414-4424.

Fujisawa, N., Furubayashi, K., Fukushima, M., Yamamoto M., Komai, T., Ootsuka, K., Kawabe, Y. 2011. Evaluation of the Iron(II)-binding abilities of humic acids by complexometric titration using colorimetry with ortho-phenanthroline. Humic Substances Research 8:1-6.

Guezzen, B., and Didi, M.A. 2012. Removal of Zn(II) from aqueous acetate solution using Di (2-ethylhexyl) phosphoric acid and tributylphosphate. International Journal of Chemistry 4:32-41.

Guo, M., Perez, C., Wei, Y., Rapoza, E., Su, G., Bou-Abdallah, F., Chasteen, N.D. 2008. Iron-binding properties of plant phenolics and cranberry's bio-effects. Dalton Transfers 43:4951-4961. 
Gupta, V., Smemo, K., Yavitt, J.B., Fowle, D., Branfireun, B. 2013. Stable isotopes reveal widespread anaerobic methane oxidation across latitude and peatland type. Environmental Science and Technology 47:8273-8279.

$\mathrm{Hu}, \mathrm{Q}$. 2011. Simlutaneous separation and quantitation of iron and transition species using LC-ICP-MS. American Journal of Analytical Chemistry 2:675-682.

Kane ES, Turetsky MR, Harden JW, McGuire AD, Waddington JM. 2010. Seasonal ice and hydrologic controls on dissolved organic carbon and nitrogen concentrations in a boreal rich fen. Journal of Geophysical Research-Biogeosciences, doi:10.1029/2010JG001366.

Kane, E.S., Chivers, M.R., Turetsky, M.R., et al. 2013. Response of anaerobic carbon cycling to water table manipulation in an Alaskan rich fen. Soil Biology and Biochemistry 58:50-60.

Keller JK, Bridgham SD. 2007. Pathways of anaerobic carbon cycling across an ombrotrophicminerotrophic peatland gradient. Limnology and Oceanography, 52 (1), 96-107

Keller JK, Takagi KK. 2013. Solid-phase organic matter reduction regulates anaerobic decomposition in bog soil. Ecosphere, 4:54.

Knorr, K.H., Blodau, C., 2009. Impact of experimental drought and rewetting on redox transformations and methanogenesis in mesocosms of a northern fen soil. Soil Biology and Biochemistry, 41 (6), 1187-1198.

Komadel, P., Stucki, J.W. Quantitative assay of minerals for $\mathrm{Fe}^{2+}$ and $\mathrm{Fe}^{3+}$ using 1,10phenanthroline: III. A rapid photochemical method. Clays and Clay Minerology 36:379381

Kothwala, D.N., von Wachenfeldt, E., Koehler, B., Tranvik, L.J. 2012. Selective loss and preservation of lake water dissolved organic matter fluorescence during long-term dark incubations. Science of the Total Environment 433:238-246.

Kothwala. D.N., Stedmon, C.A., Müller, R.A., Weyhenmeyer, G.A., Köhler, S.J., Tranvik, L.J. 2013. Controls of dissolved organic matter quality: Evidence from a largescale boreal lake survey. doi: 10.1111/gcb.12488

Lawaetz, A.J., and Stedmon, C.A. 2009. Fluorescence intensity calibration using the Raman scatter peak of water. Applied Spectroscopy 8:936-940. 
Lipson, DA., Jha, M., Raab, T.K., Oechel, W.C. 2010. Reduction of iron (III) and humic substances plays a major role in anaerobic respiration in an Arctic peat soil. Journal of Geophysical Research, 115, G00I06, doi:10.1029/2009JG001147

Lovely, D.R., and Philips, E.J.P. 1986. Availability of ferric iron for microbial reduction in bottom sediments of the freshwater tidal Potomac River. Applied Environmental Microbiology 52:751-757.

Morris, P.J., Waddington, J.M., Benscoter, B.W., Turetsky, M.R. 2011 Conceptual frameworks in peatland ecohydrology: looking beyond the two-layered (acrotelmcatotelm) model. Ecohydrology 4(1):1-11.

Nilsson M, Oquist M. 2009. Partitioning litter mass loss into carbon dioxide and methane in peatland ecosystems. AGU Geophysical Monograph, 154, 131-144. 10.1029/2008GM000819.

Olefeldt, D., Devito, K.J., Turetsky, M.R. 2013. Sources and fate of terrestrial dissolved organic carbon in lakes of a Boreal Plains region recently affected by wildfire.

Biogeosciences Discussions 10:6093-6141.

Page, S.E., Sander, M., Arnold, W.A., McNeill, K. 2012. Hydroxyl radical formation upon oxidation of reduced humic acids by oxygen in the dark. Environmental Science and Technology 46:1590-1597

Pepper, S.E., Borkowski, M., Richmann, M.K., Reed, D.T. 2010 Determination of ferrous and ferric iron in aqueous biological solutions. Analytica Chimica Acta 663:172177.

Potvin, L.R., Kane, E.S., Chimner, R.A., Kolka, R.K., Lilleskov, E.A. 2014. Effects of water table position and plant functional group on plant community, aboveground production, and peat properties in a peatland mesocosm experiment (PEATcosm). Plant and Soil DOI 10.1007/s11104-014-2301-8

Singh, S., Inamdar, S., Scott, D. 2013. Comparison of two PARAFAC models of dissolved organic matter fluorescence for a Mid-Atlantic forested watershed in the USA. Journal of Ecosystems. Available online at http://dx.doi.org/10.1155/2013/532424

Sinsabaugh, R.L., Reynolds, H., Long, T.M. 2000. Rapid assay for aminohydrolase (urease) activity in environmental samples. Soil Biology and Biochemistry 32:2095-2097. 
Skogerboe, R.K., and Wilson, S.A. 1981. Reduction of ionic species by fulvic acid. Analytical Chemistry 53:28-232.

Stedmon, C.A., and Bro, R. 2008. Characterizing dissolved organic matter fluorescence with parallel factor analysis: a tutorial. Limnology and Oceanography: Methods 6:572579 .

Tfaily, M.M., Hamdan, R., Corbett, J.E., Chanton, J.P., Glaser, P.H., Cooper, W.T. 2013. Investigating dissolved organic matter decomposition in Northern peatlands using complimentary analytical techniques. Geochmica et Cosmochimica Acta http://dx.doi.org/10.1016/j.gca.2013.03.002

Thurman, E.M. 1985. Organic geochemistry of natural waters. ISBN 90-247-3143-7

Vile, M.A., Bridgham, S.D., Wieder, S.K. 2003. Responses of anaerobic carbon mineralization rates to sulfate amendments in a boreal peatland. Ecological Applications 13(3):720-734

Viollier, E., Inglett, P.W., Hunter, K., Roychouhury, A.N., Van Cappelen, P. 2000. The ferrozine method recisited: $\mathrm{Fe}(\mathrm{II}) / \mathrm{Fe}(\mathrm{III})$ determination in natural waters. Applied Geochemistry 15:785-790.

Van de Voorde, I., Pinoy, L., Coutijn, E., Verpoort, F. 2005. Influence of acetate ions and the role of the diluents on the extraction of copper (II), nickel (II), cobalt (II), magnesium (II), and iron (II,III) with different types of extractants. Hydrometallurgy 78:92-106.

Weishaar, J.L., Aiken, G.R., Bergamaschi, B., Fram, M.S., Fuji, R., Mopper, K. 2003. Evaluation of specific ultraviolet absorbance as an indicator of the chemical composition and reactivity of dissolved organic carbon. Environmental Science and Technology 37(20):4702-4708.

Worrall, F., Burt, T., Jaeban, R., Warburton, J., Sheddon, R. 2002. Release of dissolved organic carbon from upland peat. Hydrological Processes, 16:3487-3504.

Yamamoto. M., Nishida, A., Otsuka, K., Komai, T., Fukushima, M. 2010. Evaluation of the binding of iron(II) to humic substances derived from a compost sample by a colorimetric method using ferrozine. Bioresource Technology 101:4956-4960.

US EPA. 1980. Method 8008, Iron, Total. Federal Register, June 27, 1980; 45 $(126: 43459)$ 


\section{Tables and Figures}

Table 1. Physico-chemical parameters for samples used in method comparison. Bog samples represent a mean value ( $\mathrm{n}=5$ samples each).

\begin{tabular}{|c|c|c|c|c|c|c|c|c|c|c|c|c|c|c|c|}
\hline Sample & SUVA $_{254}{ }^{a}$ & $\mathbf{E 2}^{b}$ & $E 4^{c}$ & DOC $^{d}$ & DOC:TDN $^{e}$ & $\mathbf{H}_{\mathrm{P}}^{f}$ & $\mathbf{R I}^{g}$ & $\mathrm{FI}^{h}$ & $\% \mathrm{Cl}^{i}$ & $\% \mathrm{C2}^{i}$ & $\% \mathrm{C3}^{i}$ & $\% \mathrm{C}^{i}$ & $\% \mathrm{C5}^{i}$ & $\%_{\mathrm{C} 6^{i}}$ & $\% \mathrm{C}_{\mathrm{a}}: \% \mathrm{C}_{\mathrm{c}}{ }^{j}$ \\
\hline Rich Fen & 4.07 & 4.45 & 14.88 & 58.28 & 23.31 & 15.74 & 0.77 & 1.16 & 0.30 & 0.30 & 0.30 & 0.08 & 0.00 & 0.02 & 20.47 \\
\hline Cedar Swamp & 2.89 & 4.61 & 3.41 & 32.55 & 18.82 & 13.49 & 0.68 & 1.17 & 0.34 & 0.26 & 0.27 & 0.09 & 0.01 & 0.03 & 7.51 \\
\hline Bog Sedge & 4.82 & 3.71 & 4.88 & 98.60 & 34.96 & 12.22 & 0.64 & 1.14 & 0.27 & 0.19 & 0.16 & 0.15 & 0.19 & 0.04 & 0.80 \\
\hline Bog Ericoid & 4.66 & 4.17 & 7.62 & 116.00 & 40.42 & 14.07 & 0.65 & 1.12 & 0.28 & 0.21 & 0.17 & 0.12 & 0.19 & 0.04 & 0.63 \\
\hline Bog High WT & 3.93 & 4.21 & 8.10 & 81.98 & 30.41 & 13.07 & 0.63 & 1.15 & 0.28 & 0.16 & 0.14 & 0.19 & 0.18 & 0.05 & 1.08 \\
\hline Bog Low WT & 3.75 & 4.50 & 19.82 & 146.75 & 35.78 & 16.89 & 0.67 & 1.11 & 0.27 & 0.21 & 0.20 & 0.09 & 0.21 & 0.02 & 0.45 \\
\hline
\end{tabular}

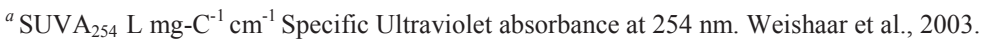

${ }^{b} \mathrm{E} 2$ Unitless. $\mathrm{A}_{\lambda 254}: \mathrm{A}_{\lambda 365}$ Index of aromaticity (UV-Vis). Worrall et al., 2002

${ }^{c}$ E4 Unitless. $\mathrm{A}_{\lambda 465}: \mathrm{A}_{\lambda 665}$. Index of oxygen content (UV-Vis). Worrall et al., 2002; Osborne et al., 2007.

${ }^{d}$ DOC mg L ${ }^{-1}$

${ }^{e}$ DOC:TDN Unitless.

${ }^{f} \mathrm{H}_{\mathrm{P}}$ Unitless. Index of humification (fluorescence). He et al., 2013.

${ }^{g}$ RI Unitless. Redox index (fluorescence). Miller et al., 2006.

${ }^{h}$ FI Unitless. Fluorescence index (Johnson et al., 2012).

${ }^{i} \%$ C1-6 Parallel Factor Analysis scores; \% of total modeled fluorescence; this work.

${ }^{j} \% \mathrm{C}_{\mathrm{a}}: \% \mathrm{C}_{\mathrm{c}}$ Ratio of $\% \mathrm{C} 4: \% \mathrm{C} 5$ (Kothwala et al., 2012). 
Table 2. Excitation-Emission maxima and putative identities of PARAFACderived fluorescence components.

\begin{tabular}{ccl}
\hline 1 & $240,325 / 420$ & Fulvic-like $^{c}$ \\
2 & $240,325 / 525$ & Condensed aromatic; high MW humic $^{b, c}$ \\
3 & $255,375 / 450$ & Less-condensed humic or fulvic \\
4 & $250 / 450$ & $\begin{array}{l}\text { Terrestrial humic or fulvic (photo- } \\
\text { refractory) }\end{array}$ \\
5 & $335 / 460$ & Terrestrial humic or fulvic $^{b}$ \\
6 & $275 / 328$ & Low MW, phenolic, microbial \\
\hline
\end{tabular}

${ }^{a}$ Cory and McKnight (2005)

${ }^{b}$ Olefeldt et al. (2013)

${ }^{c}$ Kothawla et al. (2013) 
Table 3. Loadings along the first two principal components corresponding to PCA of sample porewater chemistry.

\begin{tabular}{ccc}
\hline PCA Loadings & PC 1 (29.73\%) & PC 2 (25.50\%) \\
\hline \% Recovery $o-P$ & -0.039 & -0.251 \\
SUVA254 & -0.091 & 0.028 \\
E2 & -0.036 & -0.013 \\
E4 & -0.046 & 0.241 \\
DOC & -0.103 & 0.438 \\
DOC:TDN & -0.186 & 0.226 \\
Hp & 0.256 & 0.356 \\
RI & 0.319 & 0.149 \\
FI & 0.000 & -0.386 \\
\%C1 & 0.185 & -0.320 \\
\%C2 & 0.429 & 0.033 \\
\%C3 & 0.416 & 0.038 \\
\%C4 & -0.362 & -0.155 \\
\%C5 & -0.259 & 0.330 \\
\%C6 & -0.324 & -0.226 \\
Ca:Cc & 0.283 & -0.221 \\
\hline
\end{tabular}


Table 4. Loadings of chemistry data along the two latent variables most explanatory of $o$-phenanthroline method performance. Euclidean distance is calculated from the origin.

\begin{tabular}{cccc}
\hline Variable & LV 1 (24.10\%) & LV 3 (24.97\%) & Euclidean Distance \\
\hline SUVA $_{254}$ & 0.093 & 0.088 & 0.128 \\
E2 & -0.030 & 0.200 & 0.202 \\
E4 & -0.227 & 0.215 & 0.313 \\
DOC & -0.408 & 0.233 & 0.470 \\
DOC:TDN & -0.129 & 0.268 & 0.297 \\
Hp & -0.44 & -0.171 & 0.472 \\
RI & -0.197 & -0.348 & 0.400 \\
FI & -0.358 & -0.083 & 0.367 \\
$\% \mathrm{C} 1$ & 0.224 & -0.164 & 0.278 \\
$\% \mathrm{C} 2$ & -0.115 & -0.376 & 0.393 \\
$\% \mathrm{C} 3$ & -0.114 & -0.390 & 0.406 \\
$\% \mathrm{C} 4$ & 0.245 & 0.315 & 0.399 \\
$\% \mathrm{C} 5$ & -0.299 & 0.271 & 0.404 \\
$\% \mathrm{C} 6$ & 0.350 & 0.222 & 0.414 \\
$\mathrm{C}_{\mathrm{a}}: \mathrm{C}_{\mathrm{c}}$ & 0.219 & -0.283 & 0.358 \\
\hline
\end{tabular}




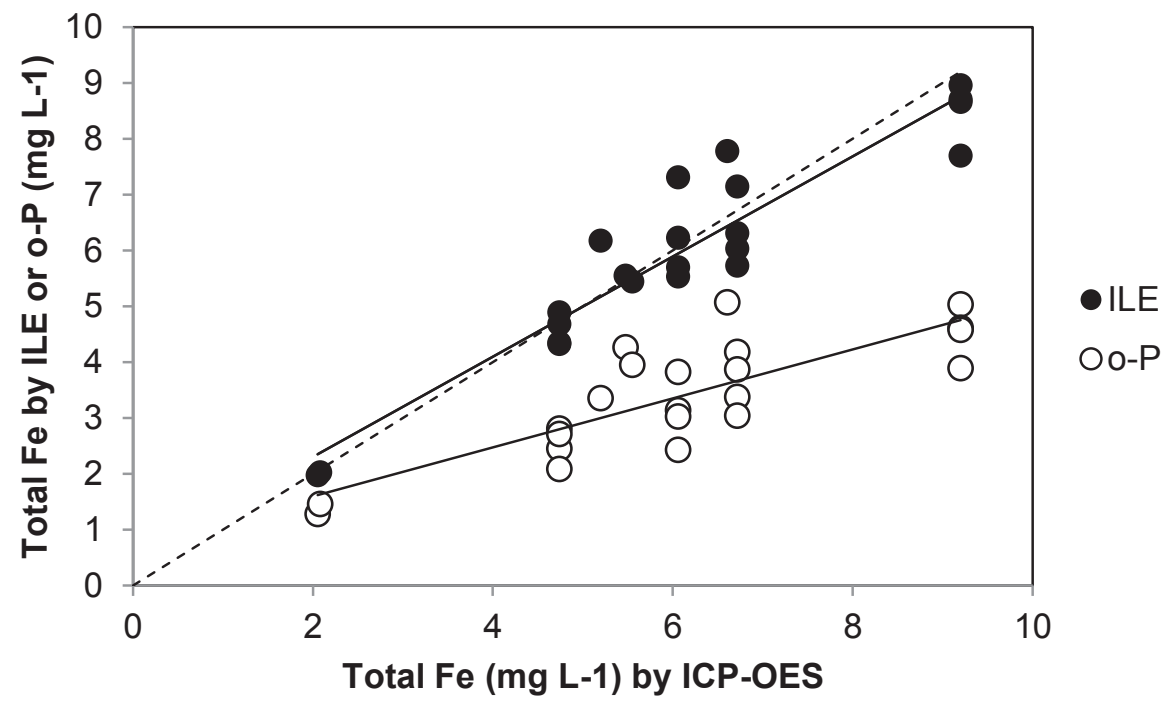

Figure 1: ILE yielded quantitative results (vs ICP-OES derived total $\mathrm{Fe})$ in DOM-rich matrices $\left(\mathrm{y}=0.90 \mathrm{x}+0.5036, \mathrm{R}^{2}=0.89, \mathrm{~F}=169.76\right)$ whereas $o$-phenanthroline experienced reduced accuracy $(\mathrm{y}=0.44 \mathrm{x}+$ $\left.0.71, \mathrm{R}^{2}=0.67, \mathrm{~F}=46.93\right)$. 

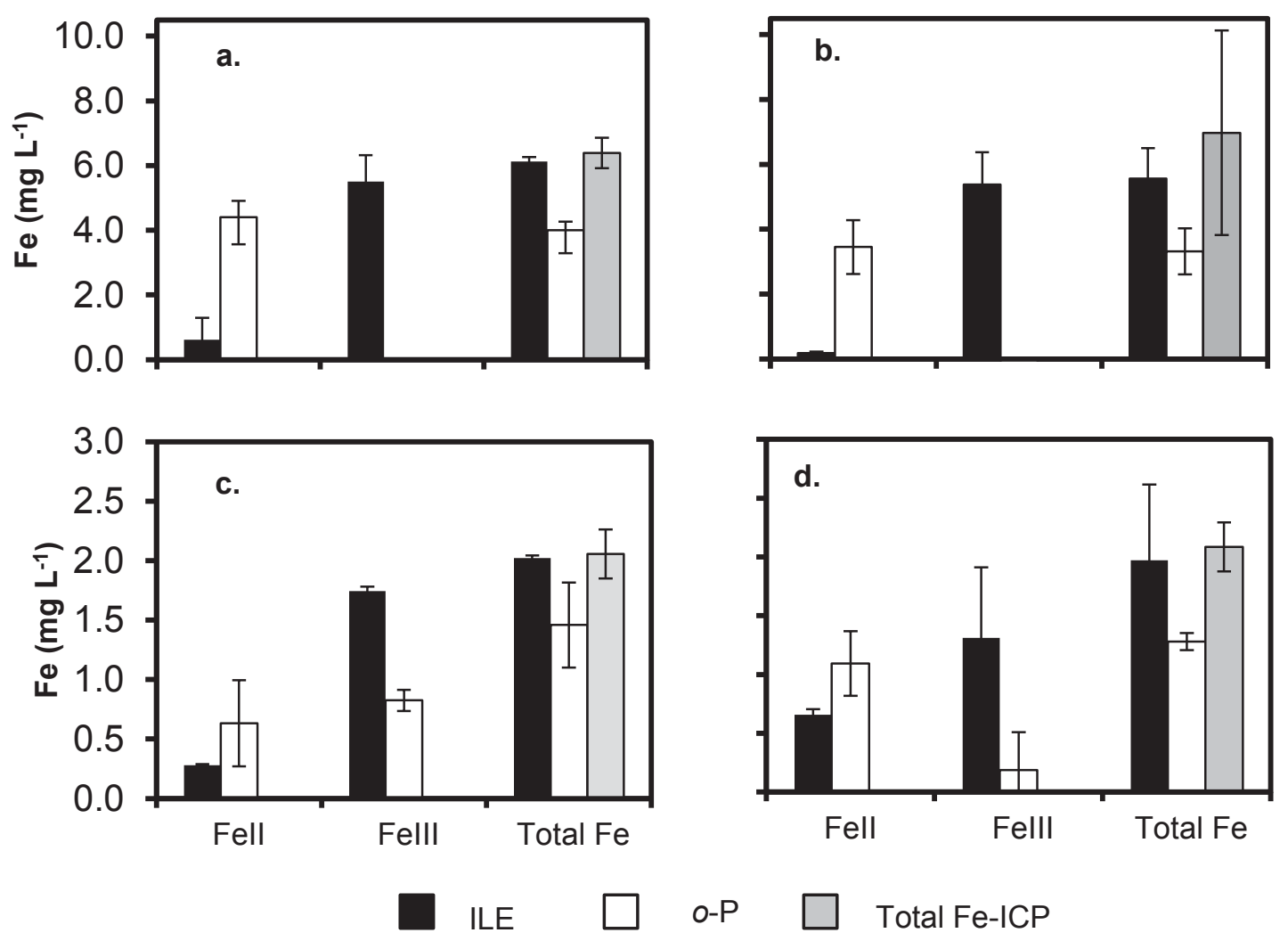

Figure 2: $o$-phenanthroline underestimated total $\mathrm{Fe}$, leading to estimates of $\mathrm{Fe}^{3+}$ $53-100 \%$ less than ILE in four distinct peatlands a. Sphagnum bog high water table; b. Sphagnum bog Ericoid community low water table; c. rich cedar fen; d. rich Sphagnum peatland). Error bars depict 1 standard deviation of replicate measurements for ILE $(\mathrm{n}=10), o-\mathrm{P}(\mathrm{n}=6)$ and Total Fe-ICP $(\mathrm{n}=10)$. 

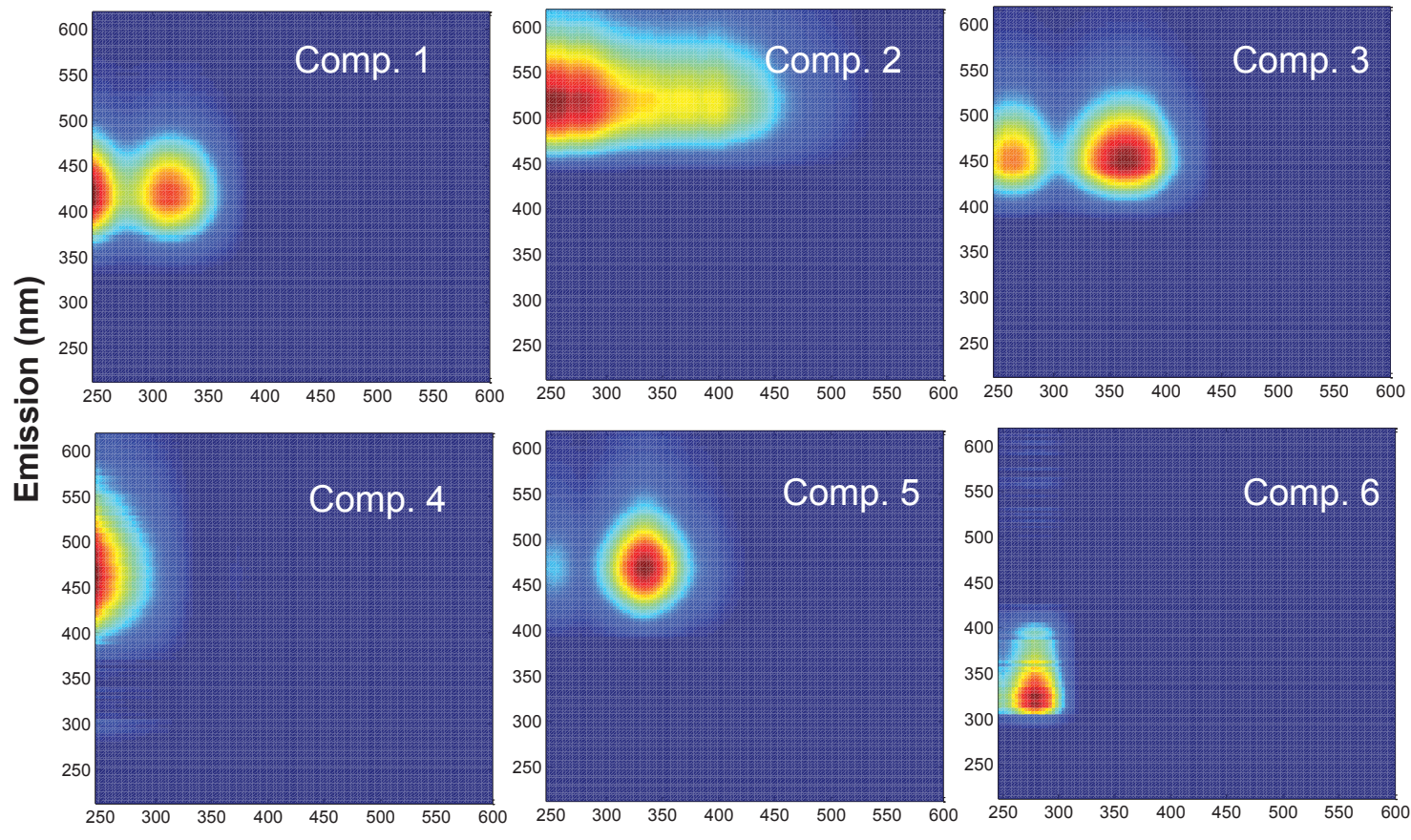

\section{Excitation (nm)}

Figure 3: PARAFAC analysis revealed six fluorescence components, explaining $>99 \%$ of fluorescence in sample EEMs. 


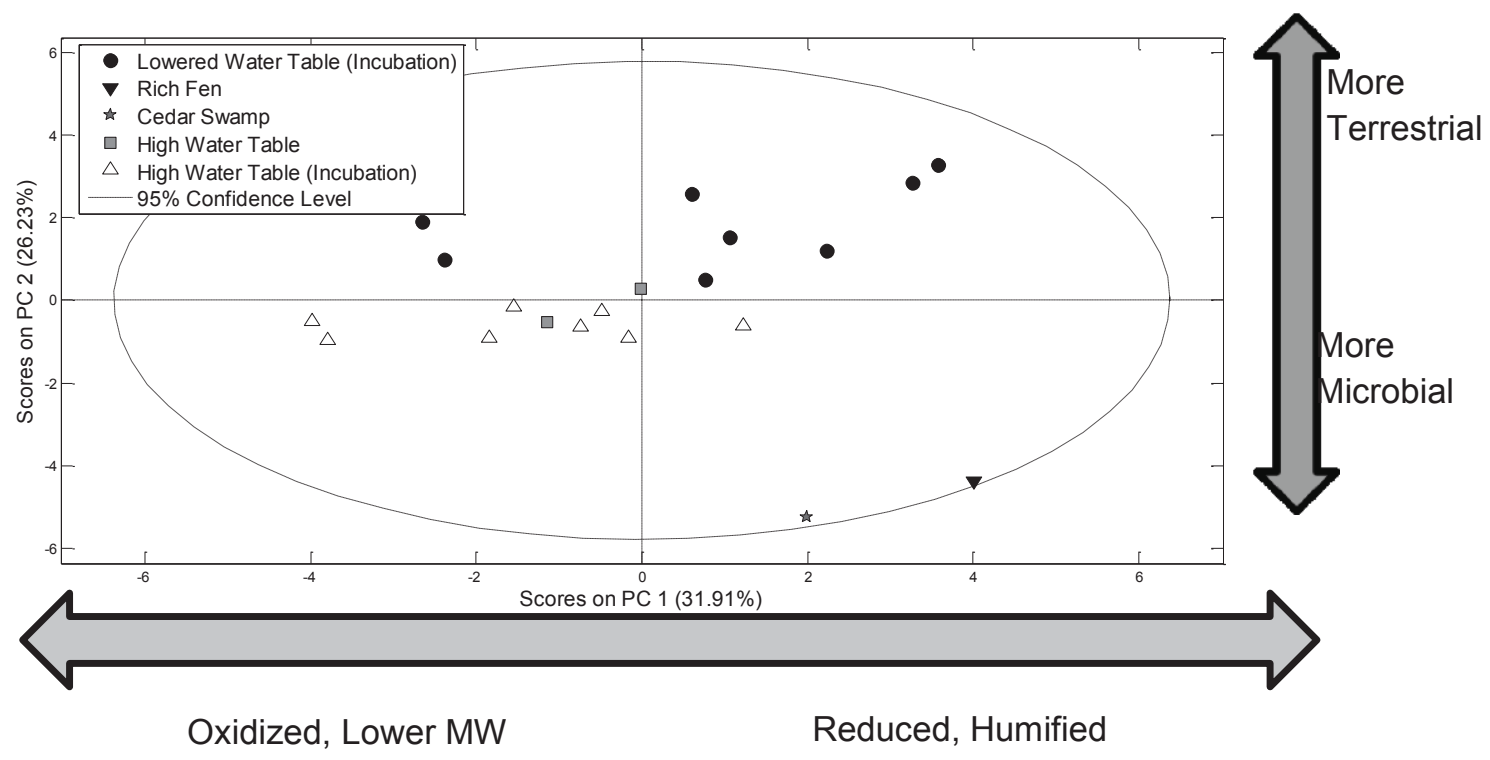

Fig 4. Loadings along the first two principal components corresponding to PCA of sample porewater chemistry. Labeled arrows indicate general trends derived from loadings. 


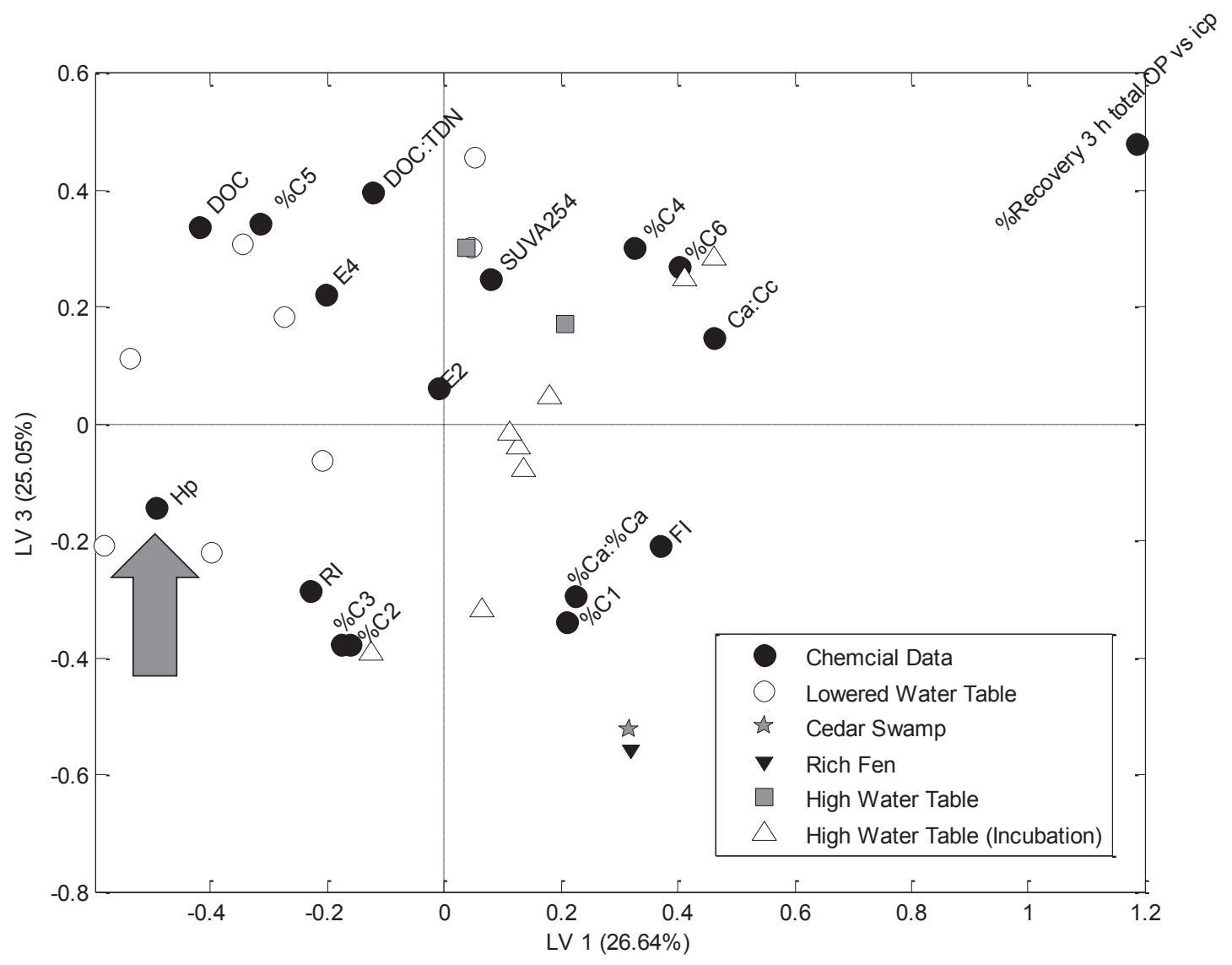

Figure 5. A PLS model found that $\mathrm{H}_{\mathrm{P}}$ (indicated by the shaded arrow) is the most significant chemical predictor antagonistic to $o$ phenanthroline method performance. 


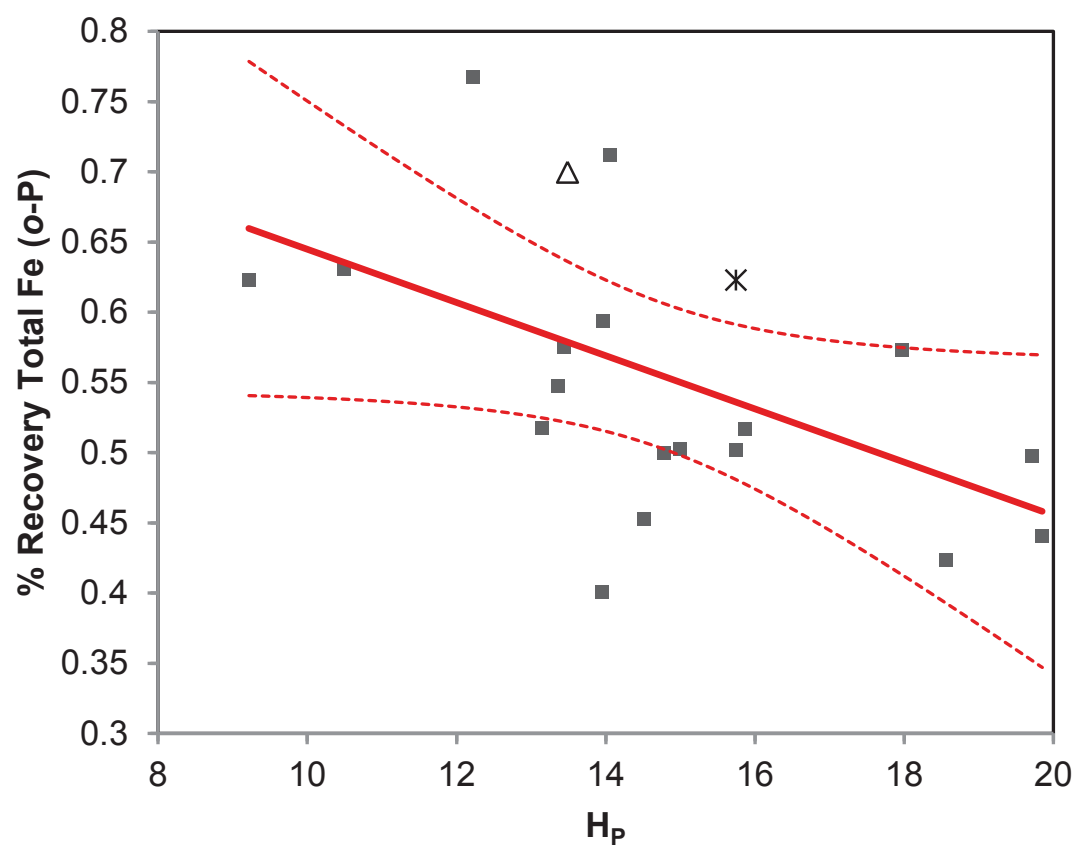

Figure 6. The recovery of total $\mathrm{Fe}$ by the $o$-phenanthroline method declined as the humification of dissolved organic matter, as indicated by humification index Hp, increased $\left(\mathrm{R}^{2}=0.28, \mathrm{~F}=13.49, \mathrm{p}=0.018\right)$. The Alaskan (asterisk) and Michigan cedar (open triangle) rich fens were identified as outliers but are still included in this regression. Bog samples outside of the $95 \%$ confidence interval projected near the origin in the PLS analysis, indicating that fluorescence and UV-Vis spectroscopy alone may not provide a full appraisal of DOM-Fe interactions. 


\section{Appendix A}

Table 5: Raw data collected during this experiment

\begin{tabular}{|c|c|c|c|c|c|c|c|c|c|c|c|c|c|c|c|c|c|c|c|c|c|c|c|c|c|c|}
\hline & III LE & $11 \mathrm{LE}$ & . & & & & Iotal & & & & & & & & 365 & A465 & A665 & & E4 & DOC & TDN & DOC & $\mathrm{Ca}: \mathrm{Cc}$ & $\mathrm{Hp}$ & & \\
\hline $\mathrm{hFen}$ & 1.092826 & $5 \quad 1.312$ & & 346 & 161.092826 & 0.187258901 & 1.280084 & & & & 0.958637 & 2.055 & 0. & 2.3707 & 0.5326 & 0.0967 & 0.0065 & & 14.87 & 58.28 & $2.5^{\circ}$ & & & & & \\
\hline & & 1.742459 & 69 & 90 & & $\begin{array}{l}825432268 \\
158055\end{array}$ & 8. 1.458218 & 0 & & 0.699721 & $\begin{array}{l}1 \\
0.97047\end{array}$ & 2.0 & 0. & 0.94076 & 0.204 & 0.04184 & $\begin{array}{ll}40.01228 \\
4\end{array}$ & 4.611569 & 3.407166 & 32.55 & & $\begin{array}{ll}318.81503 \\
\end{array}$ & & 8 & & \\
\hline & 45592 & 5.322269 & & & & 55 & & & & 13 & & 6.609 & & 4.7485 & 1.2809 & 0.3354 & $\begin{array}{ll}4 & 0.0687\end{array}$ & 3.707159 & 4.882096 & 98.6 & & & & & & \\
\hline & & 3.858866 & 866 & & & & & & & & & 5.552 & & 1034 & & & & & 7.616 & 116 & & & & & & \\
\hline & & & & & & & 54.185858 & & & & & & & & & & & & & & & & & & & \\
\hline & & & & & & & & & & & & & & & & & & & & & 1.9 & & & & & \\
\hline & & & & & & & & & & & & & & & & & & & & & & & & & & \\
\hline & & & & & & & & & & & & & & & & & & & & & & & & & & \\
\hline & & & & & & & & & & & & & & & & & & & & & & & & & & \\
\hline & & & & & & & & & & & & & & & & & & & & & & & & & & \\
\hline & & & & & & & & & & & & & & 318 & & & & & & & & & & & & \\
\hline & & & & & & & & & & & & & & & & $\begin{array}{l}0.248649 \\
0.2469\end{array}$ & & & & 178 & & & & 13 & $\begin{array}{ll}415 \\
583\end{array}$ & \\
\hline & & & & & & & & & & & & & & & & & & & & & 4 & & & & & \\
\hline & & & & & & & & & & & & 4.74 & & 5.2 & 1.1 & 0.2 & & & & 12 & 4.6 & & 64 & $\begin{array}{lll}4 & 17.98312\end{array}$ & & \\
\hline & & & & & & & & & & & & 9.2 & & & 1.734699 & 0.32 & & & & 159 & 3.68 & & & & & \\
\hline & & & & & & & & & & & & & & & & & & & & 7 & 4 & & & & & \\
\hline & & & & & & & & & & & & & & & & & & & & & 2.68 & & & & & \\
\hline & & & & & & & & & & & & & & & & & & & & 127 & & & & & & \\
\hline d486 & 0.238 & 8.72 & 8.958 & 80.027294 & $4 \quad 1.31266$ & 9442 & 1210 & 34483 & 15378 & 23055 & 0.973696 & & 13016 & 5.3737 & 1.30585 & 2778 & 173 & 1509 & 5.06069 & 162.7 & & 6975 & 68770 & 8.570 & 0.829958 & 087 \\
\hline
\end{tabular}




\section{Appendix B}

Table 6: Key to Table 5

Sample............Name of Sample

FeII ILE............. $\mathrm{Fe}^{2+}$ recovered by ILE $\left(\mathrm{mg} \mathrm{L}^{-1}\right)$

FeIII ILE............. $\mathrm{Fe}^{3+}$ recovered by ILE $\left(\mathrm{mg} \mathrm{L}^{-1}\right)$

Total ILE.......... Sum of $\mathrm{Fe}^{2+} \mathrm{Fe}^{3+}$ recovered by ILE $\left(\mathrm{mg} \mathrm{L}^{-1}\right)$

II:III ILE.......... Ratio of $\mathrm{Fe}^{2+}: \mathrm{Fe}^{3+}$ recovered by ILE

FeII OP $3 \mathbf{h} \ldots \ldots \ldots \ldots \mathrm{Fe}^{2+}$ recovered by $o$-phenanthroline $\left(\mathrm{mg} \mathrm{L}^{-1}\right)$

FeIII OP $3 \mathbf{h} \ldots \ldots \ldots \ldots \mathrm{Fe}^{3+}$ estimated by $o$-phenanthroline $\left(\mathrm{mg} \mathrm{L}^{-1}\right)$

Total OP 3h.......... Total Fe recovered by $o$-phenanthroline $\left(\mathrm{mg} \mathrm{L}^{-1}\right)$

o-p vs ILE Tot Fe.......... Ratio of Total Fe $(o-\mathrm{P})$ to Total Fe (ILE)

o-P vs ILE FeII........... Ratio of $\mathrm{Fe}^{2+}$ (o-phenanthroline) tot $\mathrm{Fe}^{2+}$ (ILE)

\%Recovery $3 \mathrm{~h}$ total OP vs icp........... Total Fe by $o$-phenanthroline divided by total Fe by ICP-OES

\% Recovery ILE.......... Total Fe by ILE divided by Total Fe by ICP-OES

Total Fe ICP.......... Total Fe determined directly by ICP-OES ( $\left.\mathrm{mg} \mathrm{L}^{-1}\right)$

SUVA254.

A254..........UV Absorbance at $254 \mathrm{~nm}$

A365..........UV Absorbance at $365 \mathrm{~nm}$

A465..........UV Absorbance at $465 \mathrm{~nm}$

A665..........UV Absorbance at $665 \mathrm{~nm}$

E2 .........A254/A365

E4 ..........A465/A665

DOC........... Dissolved organic carbon $\left(\mathrm{mg} \mathrm{L}^{-1}\right)$

TDN........... Total dissolved nitrogen $\left(\mathrm{mg} \mathrm{L}^{-1}\right)$

DOC:TDN..........Ration of DOC to TDN

Ca:Cc............Ratio of PARAFAC Component 4: Component 5

Hp...........Ratio of EEM region $(\mathrm{III}+\mathrm{V}) /(\mathrm{I}+\mathrm{II}+\mathrm{IV})$

RI.......... Ratio of reduced / oxidized component peak maxima

FI............Fluorescence index calculated from EEMs. 